\title{
De novo transcriptome assembly of brackish water flea Diaphanosoma celebensis based on short-term cadmium and benzo[a]pyrene exposure experiments
}

\author{
Bo-Mi Kim', Seunghyun Kang ${ }^{1}$, Ryeo-Ok Kim² ${ }^{2}$ Jee-Hyun Jung ${ }^{3}$, Kyun-Woo Lee ${ }^{4}$, Jae-Sung Rhee ${ }^{5^{*}}$ \\ and Young-Mi Lee 2* $^{*}$
}

\begin{abstract}
To develop a brackish water flea as a promising model for marine monitoring, Diaphanosoma celebensis were exposed to two pollutants, cadmium (Cd) and benzo[a]pyrene (BaP), which have different chemical characteristics and distinct modes of metabolic action on aquatic animals. Twenty-four hours after exposure to $\mathrm{Cd}(2 \mathrm{mg} / \mathrm{L})$ or BaP $(25 \mu \mathrm{g} / \mathrm{L})$, whole body transcriptomes were analyzed. In total, $99.6 \mathrm{Mbp}$ were assembled from nine libraries, resulting in 98,458 transcripts with an N50 of 1883 bp and an average contig length of 968 bp. Functional gene annotations were performed using Gene Ontology, Eukaryotic Orthologous Groups, and Kyoto Encyclopedia of Genes and Genomes pathway analyses. $\mathrm{Cd}$ significantly modulated endocrine and digestive enzyme system. Following BaP treatment, DNA repair and circadian rhythm related metabolisms were significantly modulated. Both the chemicals induced stress response and detoxification metabolism. This brackish water flea genomic information will be useful to monitor estuaries and coastal regions, as water fleas have been confirmed as promising sentinel models in freshwater ecosystems.
\end{abstract}

Keywords: Benzo[a]pyrene, brackish water flea, Cadmium, Diaphanosoma celebensis, Transcriptome

\section{Background}

Metals and polycyclic aromatic hydrocarbons (PAHs), which constitute a large portion of marine pollutants, are found worldwide in aquatic ecosystems due to their direct or indirect releases from sewage, industrial wastewater, oil spill, and mining $[1,2]$. The pollutants have been detected in the coastal regions of South Korea [3, 4]. They have been causing increasing concerns to aquatic environment due to difficulty in biodegradation and potentials of bioaccumulation and biomagnification to higher trophic levels via food web [5]. Cd, a non-essential metal has been reported to adversely affect the physiology and biochemistry of aquatic invertebrates $[6,7]$. Benzo[a]pyrene (BaP), PAH representative, adversely affects survival inhibition

\footnotetext{
* Correspondence: jsrhee@inu.ac.kr; ymlee70@smu.ac.kr

${ }^{5}$ Department of Marine Science, College of Natural Sciences, Incheon

National University, Incheon 22012, South Korea

${ }^{2}$ Department of Life Science, College of Natural Sciences, Sangmyung

University, Seoul 03016, South Korea

Full list of author information is available at the end of the article
}

[8], growth inhibition [9], behavior impairment [10], and reproduction problems [11] of aquatic organisms. Since the sensitivity of signal pathway and subsequent detoxification cascade are very different for chemicals, we assume that transcriptome can differentially respond to certain chemical through specific and/or common responsive metabolism. Thus, we employed two distinct chemicals to detect early molecular markers and to validate whether the application of transcriptome profiling of brackish water flea is useful method for environmental risk assessment. Understanding the molecular effects of these pollutants may provide an alternative method to predict their toxicities.

Cladocera (crustacean) are filter-feeding planktonic water flea. Daphnia species have been extensively used due to their versatility as model animals for acute and/ or chronic toxicity test and ecotoxicological application. Aquatic ecotoxicological studies mostly focus on freshwater Daphnia species such as D. magna or D. pulex (Crustacea, Cladocera, Daphniidae), while brackish water

(c) The Author(s). 2018 Open Access This article is distributed under the terms of the Creative Commons Attribution 4.0 International License (http://creativecommons.org/licenses/by/4.0/), which permits unrestricted use, distribution, and 
fleas are used sparingly. One of the advantages of freshwater Daphnia species is the availability of whole genome information and subsequent functional genomics application [12, 13]. There have been extensive transcriptome and genome studies on freshwater Daphnia species in the past decade. Estuaries and coastal regions are also important sites of ecotoxicology, with various land-derived contaminants. Sentinel organisms are useful for risk assessment and to ensuring safe and habitable environment in aquatic ecosystems. Thus, there is a need to develop robust model species for marine ecotoxicological research.

In general, most cladoceran appear to be restricted to freshwater, while Diaphanosoma celebensis (Crustacea, Cladocera, Sididae), is a euryhaline brackish water flea species distributes in tropical Asia [14]. In aquaculture industry, there is a need for developing tolerant or adapted cladoceran upon a wide range of salinity that can be applied from small aquaria to large-scale mass culture system under seawater condition. Changes in salinity have been considered as one of the crucial stressors, as even small change can directly affect osmoregulation and physiological homeostasis of marine animals. Since most aquaculture and fishery systems are located within coastal regions where the ultimate freshwater are released from inland, development of a species, which can maintain biological activity against steep salinity change, is important in aquaculture industry. They have been mainly studied in the field of aquaculture as a substitute live food $[15,16]$. D. celebensis are primary consumers and are important for energy transfer to higher trophic levels in the aquatic food web.

D. celebensis, like freshwater Daphnia species, can be easily raised under laboratory culture conditions and require similar conditions with respect to feeding, water quality $(\mathrm{pH})$, and light cycles, except for salinity and temperature. Furthermore, small size (adult 413$1112 \mu \mathrm{m})$, parthenogenetic mode of reproduction, short generation time (4-5 days), and easy maintenance in laboratory makes them suitable test organisms for marine ecotoxicological studies [17]. Genomics resource is very important for development of reliable model animal. Even though reference genomic database is absent in almost non-model animals, next generation sequencing (NGS) coupled with de novo assembly and appropriate bioinformatics tools enable us to use high quality genomic resource of certain animal.

Here, we developed a new transcriptomic resource of the brackish water flea $D$. celebensis using Illumina Hiseq 2500 platform and bioinformatics tools. To develop $D$. celebensis as a promising model animal for ecotoxicogenomics, following exposure to $\mathrm{Cd}$ and $\mathrm{BaP}$, we analyzed the transcriptome and compared differentially expressed transcripts. The genomic information of $D$. celebensis will allow future investigation of molecular ecotoxicological pathways, with a particular focus on monitoring estuaries and coastal regions.

\section{Material and methods \\ Culture and chemical exposure}

The brackish water flea D. celebensis was obtained from Dr. Kyun-Woo Lee of the Korea Institute of Ocean Science and Technology and maintained in the Molecular Toxicology Laboratory of Sangmyung University since 2015 (Table 1). They were cultured in $0.2 \mu \mathrm{m}$-mesh filtered artificial seawater (Instant Ocean ${ }^{\circ}$ Sea Salt, Instant Ocean, VA, USA), 15 practical salinity unit (psu), at $25 \pm 1{ }^{\circ} \mathrm{C}$ under a $12 \mathrm{~h}: 12 \mathrm{~h}$ light/dark photoperiod. Chlorella vularis $\left(4 \times 10^{7}\right.$ cells/L) cultured in Jaworski's Medium was supplied as a food source thrice a week. All the chemicals and reagents used were of molecular biology grade and purchased from Sigma-Aldrich Co. (St. Louis, MO, USA) unless there is no description. For stock solution, $\mathrm{Cd}$ (as $2 \mathrm{mg} / \mathrm{mL}$ with $\left.\mathrm{CdCl}_{2}\right)$ and $\mathrm{BaP}(250 \mu \mathrm{g} / \mathrm{mL})$ were prepared in sterile distilled water and dimethyl sulfoxide (DMSO, Sigma-Aldrich

Table 1 Characteristics of Diaphanosoma celebensis transcriptome sequencing project in compliance with the MlxS standard

\begin{tabular}{|c|c|}
\hline Item & Description \\
\hline Investigation type & Eukaryote transcriptome \\
\hline Classification & $\begin{array}{l}\text { Eukaryota; Opisthokonta; Metazoa; Eumetazoa; } \\
\text { Bilateria; Protostomia; Ecdysozoa; Panarthropoda; } \\
\text { Arthropoda; Mandibulata; Pancrustacea; Crustacea; } \\
\text { Branchiopoda; Phyllopoda; Diplostraca; Cladocera; } \\
\text { Ctenopoda; Sididae }\end{array}$ \\
\hline Project name & $\begin{array}{l}\text { Diaphanosoma celebensis transcriptome } \\
\text { sequencing }\end{array}$ \\
\hline $\begin{array}{l}\text { Geographic location } \\
\text { name }\end{array}$ & Malaysia coastal region $\left(6^{\circ} 30^{\prime} \mathrm{N}, 103^{\circ} 30^{\prime} \mathrm{E}\right)$ \\
\hline Maintenance & Korea Institute of Ocean Science and Technology \\
\hline Provider & Dr. Kyun-Woo Lee \\
\hline $\begin{array}{l}\text { Environment } \\
\text { (biome) }\end{array}$ & ENVO_00002030 (aquatic biome) \\
\hline $\begin{array}{l}\text { Environment } \\
\text { (feature) }\end{array}$ & ENVO_01000321 (sea water environment) \\
\hline $\begin{array}{l}\text { Environment } \\
\text { (material) }\end{array}$ & ENVO_00002150 (coastal sea water) \\
\hline Tissue type & Whole body \\
\hline $\begin{array}{l}\text { Developmental } \\
\text { stage }\end{array}$ & Adult \\
\hline Sequencing method & Pyrosequencing \\
\hline $\begin{array}{l}\text { Sequencing } \\
\text { platform }\end{array}$ & Illumina Hiseq 2500 \\
\hline Assembly & Trinity \\
\hline Finishing strategy & Contig \\
\hline Bioproject number & PRJNA464191 \\
\hline Data accessibility & GGQP00000000 \\
\hline
\end{tabular}


Co.), respectively. Final DMSO concentration was used as $0.01 \%$ that showed no significant difference between control and solvent control in preliminary gene expression study (data not shown). For transcriptome analysis, $350 \mathrm{D}$. celebensis adults ( 5 days old, mature female) were treated with $\mathrm{Cd}(2 \mathrm{mg} / \mathrm{L}, 350 \mu \mathrm{L}$ from stock) and BaP $(25 \mu \mathrm{g} / \mathrm{L}$, $35 \mu \mathrm{L}$ from stock) for $24 \mathrm{~h}$, respectively, in $350 \mathrm{ml}$ of media. Concentration of $\mathrm{Cd}$ applied was $1 / 10$ of $24-\mathrm{h} \mathrm{LC}_{10}$ value $(22.67 \mathrm{mg} / \mathrm{L})$, and that of $\mathrm{BaP}$ was the highest concentration at which dead individuals were not observed in our preliminary test, based on results of [18]. Background and dissolved concentrations of both chemicals were analyzed using ICP-MP (Inductively Coupled Plasma - Mass Spectrometry (ICP-MS, PerkinElmer, NexION300, MA, USA) for $\mathrm{Cd}$, and LC-MS for BaP. Background Cd concentration of media was measured as $0.001 \mathrm{mg} / \mathrm{L}$, and $\mathrm{BaP}$ was not detected in the seawater. Dissolved concentrations of $\mathrm{Cd}$ and $\mathrm{BaP}$ were determined as $0.970 \pm 0.002 \mathrm{mg} / \mathrm{L}$ and $25 \mu \mathrm{g} / \mathrm{L}$, respectively.

\section{Illumina sequencing}

A set of RNA samples for control and each chemical, comprised of three biological samples, was not pooled (i.e. total of 9 samples were prepared for total RNA preparation; three for control; three for $\mathrm{Cd}$; three for $\mathrm{BaP})$. Total RNA was extracted using TRIzol ${ }^{\mathrm{ma}}$ Reagent (Molecular Research Center, Inc., Cincinnati, OH, USA) according to the manufacturer's instructions. DNA digestion was performed using DNase I (Sigma Aldrich, St Louis, MO, USA). Total RNA quantity (a NanoDrop ${ }^{\circ}$ ND-8000 Spectrophotometer, Thermo Scientific, Wilmington, DE, USA) and quality by A230/260 and A260/ 280 ratios (Agilent 2100 Bioanalyzer, Agilent, Böblingen, Germany) were analyzed. Samples with RNA integrity number (>7.5) were used for library preparation. Nine libraries were prepared using Tureseq $q^{\text {Tim }}$ stranded mRNA library prep Kit (Illumina, San Diego, CA, USA) at DNA link Inc. (Seoul, South Korea). Briefly, mRNA for each sample was purified and fragmented from total RNA $(1 \mu \mathrm{g})$ by two rounds of purification using poly-T oligo-attached magnetic beads. Cleaved RNA fragments primed with random hexamers were reverse transcribed into first strand cDNA using reverse transcriptase, random primers, dUTP in place of dTTP. The products were purified and enriched with PCR to create the final strand specific cDNA library. The quality of amplified libraries was verified by capillary electrophoresis (Bioanalyzer, Agilent). After QPCR using SYBR Green PCR Master Mix (Applied Biosystems, Foster City, CA, USA), libraries that were index-tagged within a pool were combined in equimolar amounts. Cluster generation occurred in the flow cell of the cBot automated cluster generation system (Illumina). Finally, nine libraries of the three groups (i.e. control, $\mathrm{Cd}$ exposure, $\mathrm{BaP}$ exposure) were subjected to Illumina RNA sequencing (Additional file 1: Table S1). The sequenced D. celebensis cDNA libraries from each individual produced a large number of reads, at 56 to 78 million per library. The flow cell loaded on HIseq 2500 sequencing system (Illumina), performed sequencing with $2 \times 100 \mathrm{bp}$ read length. We trimmed the index and adaptor sequences using Trimmomatic [19] and removed low-quality reads using the FASTX toolkit [20] with the parameters set at $-\mathrm{t}, 20 ;-\mathrm{l}, 70$; and $-\mathrm{Q}, 33$.

\section{De novo assembly and gene expression analysis}

We assembled 99.6 Mbp (49\% GC content) from nine libraries and removed low-quality reads (average quality score $<10$ ), adapters, linkers, and PCR primers via quality filtering. For de novo transcriptome assembly, strand-specific mRNA reads from all nine samples were added to Trinity (https://github.com/trinityrnaseq/trinityrnaseq/wiki) as input to create a transcriptome. These assembled reads in FASTA format were added to CD-HIT-EST (http://weizhongli-lab.org/cd-hit) to remove redundant reads. Total trinity transcripts were 102,897 with an average length of $968 \mathrm{bp}$ and an N50 length of $1883 \mathrm{bp}$ (Additional file 1: Table S2). Finally, functional annotation of transcriptome was performed via Trinotate (https://trinotate.github.io) which includes a number of different methods such as BLASTX, BLASTP, HMMER, SignalP, TMHMM and RNAMMER. After removing redundant transcripts, total annotated transcripts were 98,458 . For differentially expressed isoforms (DEI) analysis, abundance for each sample was estimated by Kallisto (https://pachterlab.github.io/kallisto) (Additional file 1: Table S3). To detect DEIs between sample 1 (control) and 2 (case), EdgeR (https://bioconductor.org/packages/release/bioc/html/edgeR.html) was performed, and three filtering processes were applied. Firstly, $>2$ fold change was calculated and genes belonging to the following range were selected: Up-regulated: $\log 2$ [case]- $\log 2$ [control] $>\log 2(2)=1$; Downregulated: $\log 2$ [case] $-\log 2[$ control] $<\log 2(1 / 2)=-1$. Secondly, genes with $p$ value below 0.05 were selected. Lastly, genes less than $0.05<$ FDR were filtered.

\section{Transcriptome annotation}

Gene Ontology (GO) and Kyoto Encyclopedia of Genes and Genomes (KEGG) pathway analyses of all contigs were performed using Blast2GO sequence annotation tool (ver. 4.0) [21]. The specific GO composition of each category is presented as a Level 2 percentage. After aligning the contigs, we analyzed three principal categories (biological processes, cellular components, and molecular function) using default parameters. BLAST search and functional domain annotation by InterProScan of Blast2GO software package assigned 2194 contigs 
to at least one GO term (Additional file 1: Table S4). Finally, the assembled data was arranged in terms of read length, gene annotation, GenBank number, E-value, species, and species accession number. We calculated mRNA expression levels using reads per kilobase of transcriptome per million mapped reads (RPKM) method [22].

\section{Results and discussion}

The aim of this study was to elucidate the potential advantages, particularly in monitoring estuaries and coastal regions, of transcriptional profiling of the brackish water flea $D$. celebensis. Based on principal BLAST hits, about 25,881 D. celebensis contigs exhibited sequence similarities to Daphnia magna transcripts, and 14,604 to Daphnia pulex transcripts (Fig. 1a). 96 and 91\% were homologous to transcripts from phylum Arthropoda and class Branchiopoda, respectively. Thus, sample preparation and sequencing had been successful; the raw read assembly was undoubtedly Cladocera. Our reference transcriptome of the brackish water flea will be valuable for studying comparative genomics in Cladocera and facilitate biomarker development for ecotoxicology studies as a sentinel species for estuaries and coastal regions.

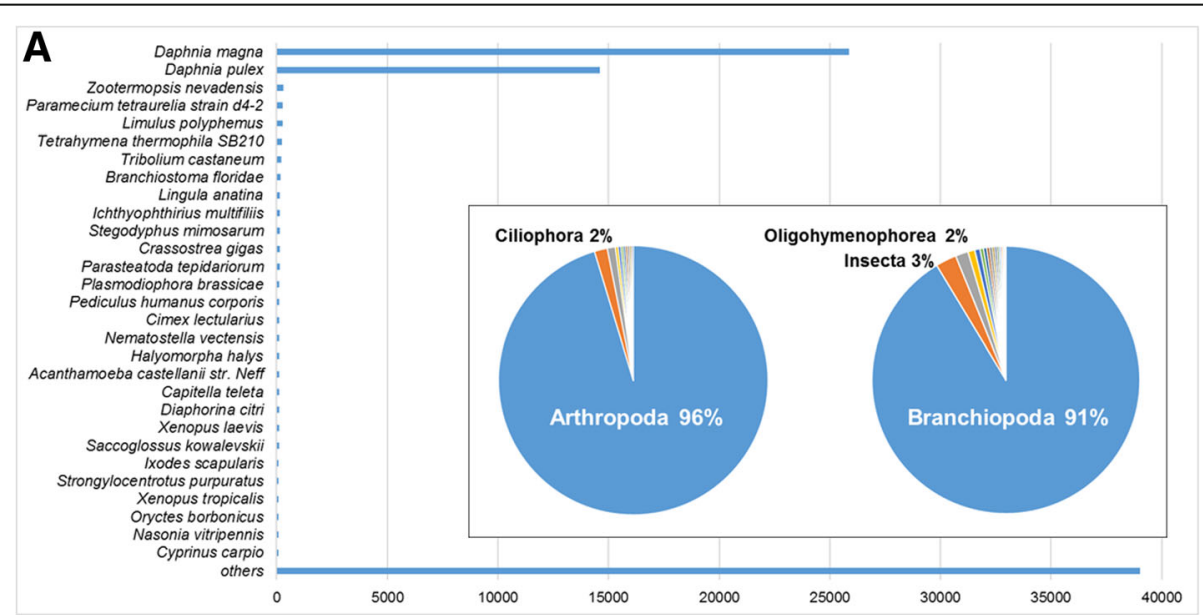

B
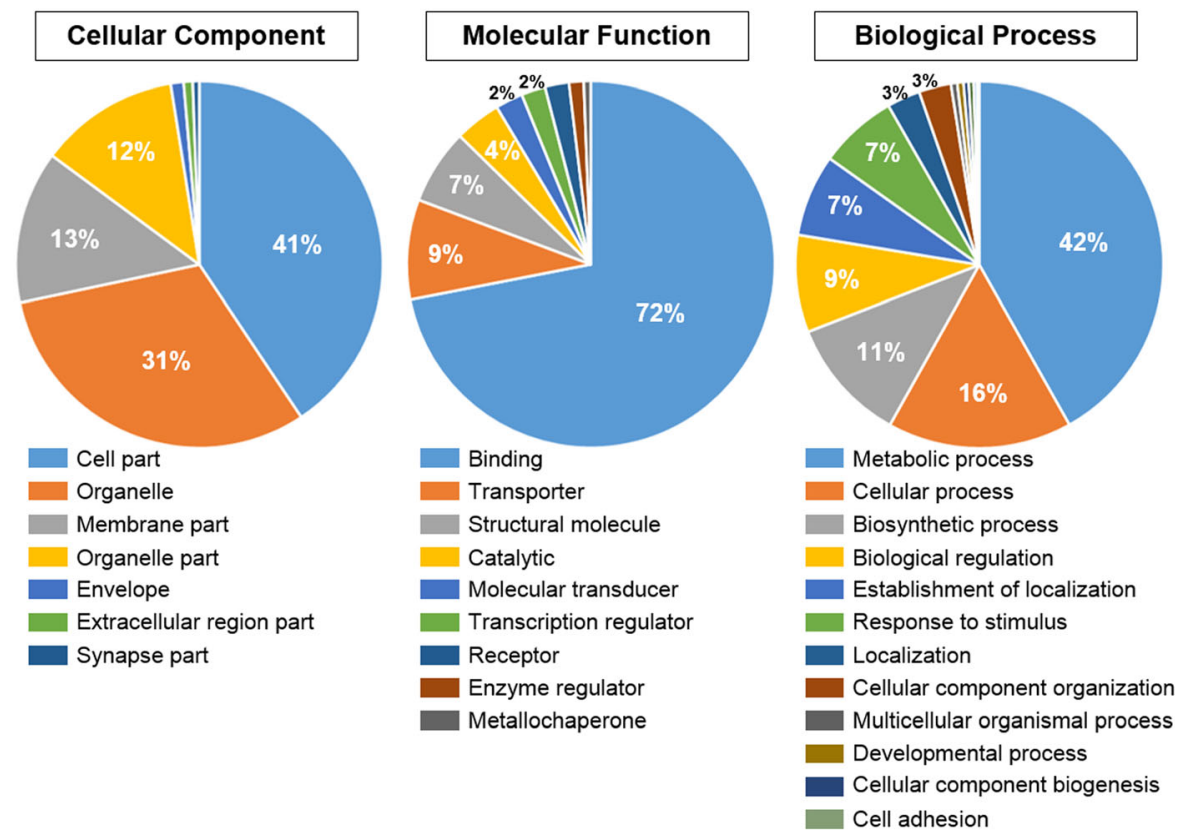

Fig. 1 a Numbers of major BLAST hits matched to Diaphanosoma celebensis transcripts at phylum and species levels. Each number is the number of orthologous gene families shared by the indicated genomic database. b Gene Ontology (GO) analyses: cellular components, molecular functions, and biological processes enriched in the $D$. celebensis transcriptome 
Diverse GO assignments analyzed by Blast2GO showed that $D$. celebensis performs several complex biological functions (Fig. 1b). In cellular components category, transcripts were assigned to cellular part (41\%), organelle (31\%), membrane part (13\%), and organelle part (12\%). In molecular function category, genes were categorized as binding (72\%), transporter (9\%), and structural molecule (7\%). In biological process category, genes were classified as metabolic (42\%), cellular (16\%) and biosynthetic (11\%). KEGG pathways analysis showed that many annotated sequences were involved in various pathways.

A total of 2901 unique genes showed significantly different mRNA expression in Cd-exposed D. celebensis criteria $> \pm 2$ fold change and $P<0.05$ (1092 transcripts upregulated; 1809 downregulated), and 3864 transcripts showed significant differences in the BaP-exposed D. celebensis (2434 transcripts upregulated; 1430 downregulated) when compared to respective controls (Fig. 2). Of upregulated transcripts, 713 mRNAs of $\mathrm{Cd}$ - and 2055 mRNAs of BaP-exposed D. celebensis were chemicalpreferentially expressed, whereas 379 mRNAs were commonly upregulated in both chemical exposures. Among downregulated transcripts, 326 mRNAs were common for both chemicals, while 1483 and 1104 mRNAs were

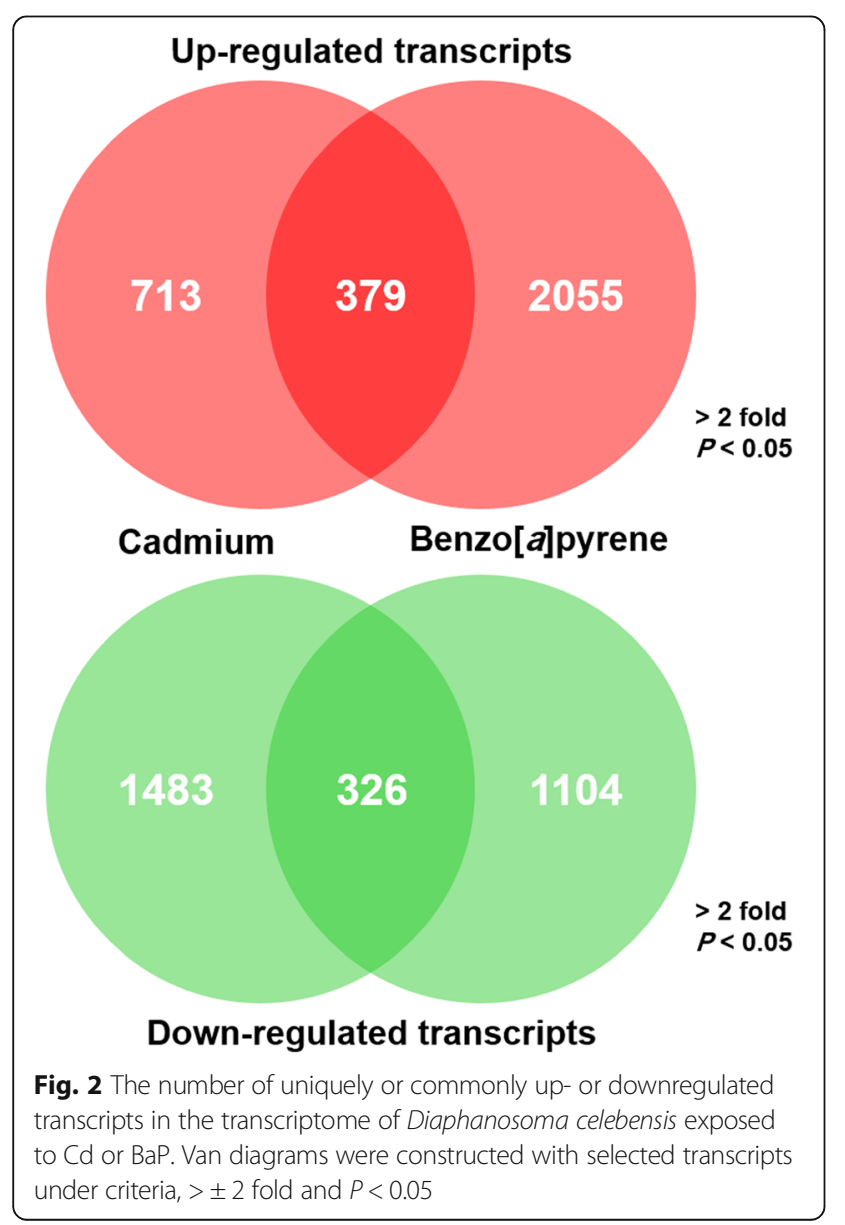

unique to $\mathrm{Cd}$ and $\mathrm{BaP}$, respectively. KEGG analysis also identified numerous enzymes uniquely or common to various metabolic pathways (Additional file 1: Table S5).

A comparative analysis of $D$. celebensis transcriptomes was performed to identify transcriptional expressions unique to each chemical exposure. Of up-regulated transcripts by $\mathrm{Cd}$ exposure $(>2$ fold change and $P<0.05$ ), mRNA expressions of vitelline membrane outer layer (VMO) protein (10.45 fold), HSP19.9 (3.48 fold), cytochrome P450 (CYP) 3036a1 (3.45 fold), and glutathione $S$-transferase sigma (GST-S; 2.43 fold) were significant. VMO protein ( $\mathrm{vmo1}$ gene) is essential in maintaining yolk and protecting eggs from microbes [23]. Effects of $\mathrm{Cd}$ on vitellogenesis are not fully explored in aquatic crustaceans. However, Cd treatment significantly increased copepods' vitellogenin $(v t g)$ gene through putative metal responsive elements (MREs) of promoter region [24]. Cd induces oxidative stress by generating reactive oxygen species (ROS) in oxygen-consuming organisms. Thus, intracellular protective mechanisms including antioxidant defense system (e.g. GSTs) and stress proteins (e.g. HSPs) [25, 26] can be actively induced by $\mathrm{Cd}$ exposure in $D$. celebensis. Although limited information on annotation and potential detoxification functions is available on CYP superfamily members in aquatic invertebrates, members of CYP $2 / 3$ families are likely involved in xenobiotics metabolism [27, 28].

Among significantly downregulated transcripts $(>-2$ fold change and $P<0.05$ ), calcium-activated chloride channel regulator (CLCA, -7.72 fold), trypsin $(-3.58$ fold), alpha-amylase ( -3.21 fold), lipase $(-2.20$ fold), and endochitinase ( -2.02 fold) were notable. CLCA regulates calcium activated chloride channels (CaCCs), which is involved in cellular physiology, such as neuronal and cardiac action, muscle contraction, and epithelial secretion [29, 30]. Cadmium can interrupt activation of $\mathrm{CaCC}$ [31]. Although function of CLCA and CaCCs are scarcely studied in aquatic invertebrates, it is assumed that $\mathrm{Cd}$ may disrupts activation of $\mathrm{CaCC}$ by inhibiting CLCA expression, as shown in the present study.

Decrease of several digestive enzymes such as trypsin, alpha-amylase, and lipase in response to $\mathrm{Cd}$ can be induced by disruption of cysteine (Cys)-containing digestive enzyme through potential binding of $\mathrm{Cd}$ to $\mathrm{Cys}$ residue [32]. Chitinase, a target of ecdysteroids, regulates crustacean molt process [33]. Thus, downregulation of endochitinase can be associated with Cd-triggered endocrine fluctuation of $D$. celebensis, but further confirmatory evidence is needed.

$\mathrm{BaP}$ exposure significantly upregulated mRNA expressions of microsomal GST ( $m g s t ; 8.58$ fold), DNA repair and recombination protein rad54 (8.29 fold), GST theta (gstt; 5.34 fold), and DNA excision repair protein ercc-1 (4.64 fold), but its treatment decreased cryptochrome1 
(cry1; -8.17 fold) and timeout/timeless-2 (- 7.38 fold). Transcriptional increases of $g s t$ family are not surprising as their molecular and biochemical involvements as phase II detoxification enzymes have extensively been studied in $\mathrm{BaP}$ biotransformation metabolism of aquatic animals. Interestingly, mRNA expressions of two DNA repair-related transcripts, rad54 and ercc-1, was significantly increased by $\mathrm{BaP}$ exposure. $\mathrm{BaP}$, a carcinogen, exerts its toxicity as benzo[a]pyrene diol epoxide (BPDE) through CYP-mediated biotransformation. BPDE can bind to DNA and produce BPDE-DNA adducts leading to mutation, carcinogenesis, and/or cell death [34]. Thus, upregulation of rad54 and ercc-1 can be associated with activation of repair metabolism by BaP-mediated DNA damage. In fact, $\mathrm{BaP}$ and/or BPDE exposures have significantly increased DNA repair genes including ercc1 and rad54 in vitro and in vivo [35-37]. Interestingly, downregulation of two transcripts, $c r y 1$ and timeout/timeless-2, which are involved in circadian clock metabolism, suggests that $D$. celebensis circadian clock (CC) metabolism can also be influenced by exposure to BaP. Regulation of $\mathrm{CC}$ is known to be closely related to xenobiotics' effects [38]. Interaction between aryl hydrocarbon receptor (AHR) signaling pathway and $\mathrm{CC}$ is essential in maintaining homeostasis; disruption of biological clock can induce hypersensitivity to environmental toxicants [39].

In conclusion, library construction and assembly were successfully conducted and the transcriptome covers essential gene repertoire of Cladocera in the present study. Finally, we present the first $D$. celebensis transcriptome and a brief comparison of differentially regulated transcripts upon $\mathrm{Cd}$ and $\mathrm{BaP}$ exposure. Our results show that the application of transcriptome profiling is a promising testing method to study effects of exposure to environmental pollutants using $D$. celebensis.

\section{Additional file}

Additional file 1: Table S1. Summary of the library construction. Table S2. Summary of the de novo transcriptome assembly results. Table S3. Transcriptional expression analysis. Table S4. Gene Ontology (GO) analysis for the three categories. Table S5. KEGG pathway analysis for uniquely or commonly up- or downregulated transcripts in the transcriptome of Diaphanosoma celebensis. (XLSX $21456 \mathrm{~kb})$

\section{Abbreviations}

AHR: Aryl hydrocarbon receptor; BaP: Benzo[a]pyrene; BPDE: Benzo[a]pyrene diol epoxide; Cd: cadmium; CLCA: Calcium-activated chloride channel regulator; CYP: Cytochrome P450; GO: Gene ontology; GST: Glutathione Stransferase; HSP: Heat shock protein; KEGG: Kyoto Encyclopedia of Genes and Genomes; PAH: Polycyclic aromatic hydrocarbon; RPKM: Reads per kilobase of transcriptome per million mapped reads

\section{Funding}

This work was supported by a grant from the National Research Foundation of Korea (NRF-2016R1A2B4009939) funded to Young-Mi Lee.

\section{Availability of data and materials}

The obtained raw RNA-seq data were deposited in the NCBI Sequence Read Archive (SRA; accession number SRR7162633-SRR7162640) under bioproject number PRJNA464191. The Diaphanosoma celebensis transcriptome shotgun assembly (TSA) project has the project accession GGQP00000000. This version of the project (01) has the accession number GGQP01000000, and consists of sequences GGQP01000001-GGQP01094075.

\section{Authors' contributions}

YML, JSR, and BMK conceived and designed research. BMK and SK analyzed the transcriptome data and statistics. ROK and KWL performed experiments. BMK, JSR, and YML wrote the manuscript with considerable input from all authors. JHJ, JSR, and YML revised the manuscript. All the authors participated during the discussion and approved of its final manuscript.

Ethics approval and consent to participate

Not applicable.

\section{Consent for publication}

Not applicable.

\section{Competing interests}

The authors declare that they have no competing interests.

\section{Publisher's Note}

Springer Nature remains neutral with regard to jurisdictional claims in published maps and institutional affiliations.

\section{Author details}

${ }^{1}$ Unit of Polar Genomics, Korea Polar Research Institute, Incheon 21990, South Korea. ${ }^{2}$ Department of Life Science, College of Natural Sciences, Sangmyung University, Seoul 03016, South Korea. ${ }^{3}$ Oil and POPs Research Group, Korea Institute of Ocean Science and Technology, Geoje 53201, South Korea. ${ }^{4}$ Korea Institute of Ocean Science and Technology, 385, Haeyang-ro, Youngdo, Busan 49111, South Korea. ${ }^{5}$ Department of Marine Science, College of Natural Sciences, Incheon National University, Incheon 22012, South Korea.

Received: 11 July 2018 Accepted: 6 November 2018

Published online: 17 November 2018

\section{References}

1. Li G, Xia X, Yang Z, Wang R, Voulvoulis N. Distribution and sources of polycyclic aromatic hydrocarbons in the middle and lower reaches of the Yellow River, China. Environ Pollut. 2006;44:985-93.

2. Sánchez-Quiles D, Marba N, Tovar-Santhez A. Trace metal accumulation in marine macrophytes: hotspots of coastal contamination worldwide. Sci Total Environ. 2017:576:520-7.

3. Yim UH, Hong SH, Shim WJ, Oh JR, Chang M. Spatio-temporal distribution and characteristics of PAHs in sediments from Masan Bay, Korea. Mar Pollut Bull. 2005;50:319-26.

4. Yang WH, Lee HJ, Kim GB. Distribution of organic matter and trace metals in surface sediments and ecological risk assessment in the Tongyeong coast. Oceanography. 2016;21:125-33.

5. Seebaugh DR, Goto D, Wallace WG. Bioenhancement of cadmium transfer along a multi-level food chain. Marine Environ Res. 2005;59:473-91.

6. Kim H, Kim JS, Kim PJ, Won EJ, Lee YM. Response of antioxidant enzymes to $\mathrm{cd}$ and $\mathrm{Pb}$ exposure in water flea Daphnia magna: differential metal and age - specific patterns. Comp Biochem Physiol. 2018;209:28-36.

7. Sharma RK, Agrawal M. Biological effects of heavy metals: and overview. J Environ Biol. 2005;26:301-13.

8. Palalnikumar L, Kumaraguru AK, Ramakritinan CM, Anand M. Biochemical response of anthracene and benzo[a]pyrene in milkfish Chanos chanos. Ecotoxicol Environ Saf. 2012;75:187-97.

9. Kim SG, Park DK, Jang SW, Lee SW, Kim SS, Chung MH. Effects of dietary benzo[a]pyrene on growth and hematological parameters in juvenile rockfish, Sebastes schlegeli (Hilgendorf). Bull Environ Contam Toxicol. 2008; 81:470-4.

10. Oliveira C, Almeida J, Guilhermino L, Soares AMVM, Gravato C. Acute effects of deltamethrin on swimming velocity and biomarkers of the common prawn Palaemon serratus. Aquat Toxicol. 2012;124-125:209-16. 
11. Choy EJ, Jo Q, Moon HB, Kang CK, Kang JC. Timecourse uptake and elimination of benzo(a)pyrene and its damage to reproduction and ensuing reproductive outputs of Pacific oyster, Crassostrea gigas. Mar Biol. 2007;151:157-65.

12. Colbourne JK, Pfrender ME, Gilbert D, Thomas WK, Tucker A, Oakley TH, Tokishita S, Aerts A, Arnold GJ, Basu MK, Bauer DJ, Cáceres CE, Carmel L, Casola C, Choi JH, Detter JC, Dong Q, Dusheyko S, Eads BD, Fröhlich T, Geiler-Samerotte KA, Gerlach D, Hatcher P, Jogdeo S, Krijgsveld J, Kriventseva EV, Kültz D, Laforsch C, Lindquist E, Lopez J, Manak JR, Muller J, Pangilinan J, Patwardhan RP, Pitluck S, Pritham EJ, Rechtsteiner A, Rho M, Rogozin IB, Sakarya O, Salamov A, Schaack S, Shapiro H, Shiga Y, Skalitzky C, Smith Z, Souvorov A, Sung W, Tang Z, Tsuchiya D, Tu H, Vos H, Wang M, Wolf YI, Yamagata H, Yamada T, Ye Y, Shaw JR, Andrews J, Crease TJ, Tang H, Lucas SM, Robertson HM, Bork P, Koonin EV, Zdobnov EM, Grigoriev IV, Lynch M, Boore JL. The ecoresponsive genome of Daphnia pulex. Science. 2011;331:555-61.

13. Nakanishi T, Kato Y, Matsuura T, Watanabe H. CRISPR/Cas-mediated targeted mutagenesis in Daphnia magna. PLoS One. 2014;9:e98363.

14. Korovchinsky NM. Redescription of Diaphanosoma celebensis Stingelin, 1900 (Crustacea, Cladocera). Hydrobiologia. 1989;184:7-22.

15. De la Peña MR. Use of juvenile instar Diaphanosoma celebensis (Stingelin) in hatchery rearing of Asian sea bass Lates calcarifer (Bloch). Isr J Aquac. 2001; 53:128-38.

16. Park JC, Park HG. Growth of the brackish water flea, Diaphanosoma celebensis, on different foods and food concentrations. Kor J Fish Aquat Sci. 2010;43:131-8

17. Marcial HS, Hagiwara A. Multigenerational effects of 17b-estradiol and nonylphenol on euryhaline cladoceran Diaphanosoma celebensis. Fish Sci. 2007;73:324-30.

18. Ikenaka Y, Sakamoto M, Nagata T, Takahashi H, Miyabara Y, Hanazato T, Ishizuka M, Isove T, Kim JW, Chang KH. Effects of polycyclic aromatic hydrocarbons (PAHs) on an aquatic ecosystem: acute toxicity and community-level toxic impact tests of benzo[a]pyrene using lake zooplankton community. J Toxicol Sci. 2013;28:131-6.

19. Bolger AM, Lohse M, Usadel B. Trimmomatic: a flexible trimmer for Illumina sequence data. Bioinformatics. 2014;30:2114-20.

20. Gordon A, Hannon G. Fastx-toolkit. FASTQ/A short-reads pre-processing tools. 2010. https://hannonlabcshledu/fastx_toolkit.

21. Conesa A, Götz S, García-Gómez JM, Terol J, Talón M, Robles M. Blast2GO: a universal tool for annotation, visualization and analysis in functional genomics research. Bioinformatics. 2005;21:3674-6.

22. Mortazavi A, Williams BA, McCue K, Schaeffer L, Wold B. Mapping and quantifying mammalian transcriptomes by RNA-seq. Nat Methods. 2008:5:621-8

23. Byrne BM, Gruber M, Ab G. The evolution of egg yolk proteins. Prog Biophys Mol Biol. 1989;53:33-69.

24. Hwang D-S, Lee K-W, Han J, Park HG, Lee J, Lee Y-M, Lee J-S. Molecular characterization and expression of vitellogenin $(\mathrm{Vg})$ genes from the cyclopoid copepod, Paracyclopina nana exposed to heavy metals. Comp Biochem Physiol C. 2010;151:360-8.

25. Kim B-M, Rhee J-S, Jeong C-B Seo JS, Park GS, Lee Y-M, Lee J-S. Heavy metals induce oxidative stress and trigger oxidative stress-mediated heat shock protein ( $h s p$ ) modulation in the intertidal copepod Tigriopus japonicus. Comp Biochem Physiol C. 2014;166:65-74.

26. Yang JH, Kim HJ, Lee SM, Kim B-M, Seo YR. Cadmium-induced biomarkers discovery and comparative network analysis in Daphnia magna. Mol Cell Toxicol. 2017;13:327-36.

27. Kim R-O, Kim B-M, Jeong C-B, Nelson DR, Lee J-S, Rhee J-S. Expression pattern of entire cytochrome P450 genes and response of defensomes in the benzo[a]pyrene-exposed monogonont rotifer Brachionus koreanus. Environ Sci Technol. 2013;47:13804-12.

28. Won E-J, Rhee J-S, Shin K-H, Jung J-H, Shim WJ, Lee Y-M, Lee J-S. Expression of three novel cytochrome P450 (CYP) and antioxidative genes from the polychaete, Perinereis nuntia exposed to water accommodated fraction (WAF) of Iranian crude oil and benzo[a]pyrene. Mar Environ Res. 2013;90:75-84.

29. Hartzell C, Putzier I, Arreola J. Calcium-activated chloride channels. Annu Rev Physiol. 2005;67:719-58.

30. Nyström EEL, Birrcenough GMH, van der Post S, Arike L, Gruber AD, Hansson GC, Johansson MEV. Calcium-activated Chloride Channel regulator 1 (CLCA1) controls mucus expansion in Colon by proteolytic activity. EBioMedicine. 2018;33:134-43. https://doi.org/10.1016/j.ebiom.2018.05.031.
31. Huang $F$, Zhang $H$, Wu M, Yang $H$, Kudo $M$, Peters CJ, Woodruff PG, Solberg OD, Lonne ML, Huang Z, Sheppard D, Fahy JV, Wolters PJ, Hogan BLM, Finkbeiner WE, Li M, Jan YN, Jan LY, Rock JR. Calcium-activated chloride channel TMEM16A modulates mucin secretion and airway smooth muscle contraction. Proc Natl Acad Sci U S A. 2012;109:16354-9.

32. Wu H, Wuan R, Li Y, Zhang X, Wang Q, Wang L. Effects of cadmium exposure on digestive enzymes, antioxidant enzymes, and lipid peroxidation in the freshwater crab Sinopotamon henanense. Environ Sci Pollut Res. 2013;20:4085-92.

33. Zou E, Bonvillain R. Chitinase activity in the epidermis of the fiddler crab, Uca pugilator, as an in vivo screen for molt-interfering xenobiotics. Comp Biochem Physiol C. 2004;139:225-30.

34. Sims P, Grover PL, Swaisland A, Pal K, Hewer A. Metabolic activation of benzo(a)pyrene proceeds by a diol-epoxide. Nature. 1974;252:326-8.

35. Averbeck $\mathrm{D}$, Averbeck $\mathrm{S}$. Induction of the genes RAD54 and RNR2 by various DNA damaging agents in Saccharomyces cerevisiae. Mutat Res. 1994;315:123-38.

36. Tung EW, Philbrook NA, Belanger CL, Ansari S, Winn LM. Benzo[a]pyrene increases DNA double strand break repair in vitro and in vivo: a possible mechanism for benzo[a]pyrene-induced toxicity. Mutat Res. 2014;760:64-9.

37. Yang J, Liu X, Niu P, Zou Y, Gong Z, Yuan J, Wu T. Dynamic changes of XPA, $X P C, X P F, X P G$ and ERCC1 protein expression and their correlations with levels of DNA damage in human bronchial epithelia cells exposed to benzo[a]pyrene. Toxicol Let. 2007;174:10-7.

38. Beaver LM, Hooven LA, Butcher SM, Krishnan N, Sherman KA, Chow ESY, Giebultowicz JM. Circadian clock regulates response to pesticides in Drosophila via conserved Pdp1 pathway. Toxicol Sci. 2010;115:513-20.

39. Anderson G, Beischlag TV, Vinciguerra M, Mazzoccoli G. The circadian clock circuitry and the AHR signaling pathway in physiology and pathology. Biochem Pharmacol. 2013;85:1405-16.
Ready to submit your research? Choose BMC and benefit from:
- fast, convenient online submission
- thorough peer review by experienced researchers in your field
- rapid publication on acceptance
- support for research data, including large and complex data types
- gold Open Access which fosters wider collaboration and increased citations
- maximum visibility for your research: over $100 \mathrm{M}$ website views per year
At BMC, research is always in progress.
Learn more biomedcentral.com/submissions 